\title{
Bilateral genu varus (bowlegs) at early childhood in Mosul
}

\author{
Yakdan Z. Alsaleem, Mahmood A. Aljumaily \\ Department of Surgery, College of Medicine, University of Mosul.
}

(Ann. Coll. Med. Mosul 2012; 38 (2): 87-90).

Received: $7^{\text {th }}$ Dec. 2011; Accepted: $2^{\text {nd }}$ Oct. 2012.

\begin{abstract}
Background: Genu varus deformity (bowlegs) is deviation of leg distal to knee toward midline, it is very common in early childhood. No data is available in apparently healthy Iraqi children.

Objective: To identify the common causes of genu varus, and to evaluate its correction.

Patients and methods: it is case series study; two hundred and thirteen children with bilateral genu varus deformities were included from Orthopedic Outpatient Clinic, Aljumhoori Teaching Hospital. The intercondylar distance was measured every 6 months during the period of follow-up which ranged between 2- 6 years.

Results: Physiological genu varus was the commonest cause, 153 children (71.8\%), their mean intercondylar distance was $3.42 \pm 0.93$, corrected spontaneously within two years. Nutritional rickets was the second cause in 58 patients (27.2\%), their mean intercondylar distance was $4.22 \pm 0.92$ corrected spontaneously with medical treatment within 4 years. Two patients had vitamin $D$ resistant rickets (hypophosphataemia), their deformities increased with growth.

Conclusion: The most common cause of bilateral genu varus was physiological, usually corrected spontaneously within two years. Nutritional rickets was the second cause which leads to more severe genu varus, and delay its correction.
\end{abstract}

Keywords: Knee, genu varus, bilateral, children.

الخلاصة

الخلفية: بعد الانحر اف الإنسي للركبتين في الطفولة المبكرة من الحالات الثائعة جدا. و لا تتوفر لنا معلومات حول هذه الحالة عند الأصحاء ظاهريا من الأطفال العر اقيين.

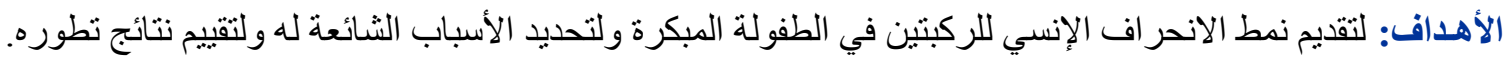

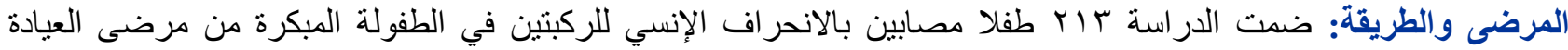
الاستثارية لجر احة العظام في المستشفى الجمهوري التعليمي. تم قياس المسافة بين الركبنين كل ستة أثنهر خلال فترة المتابعة التي لئي

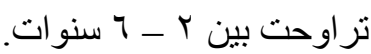

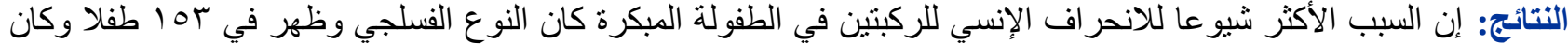

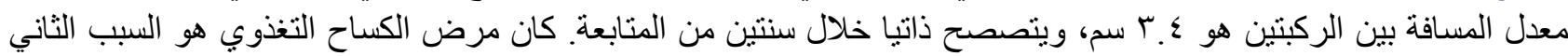

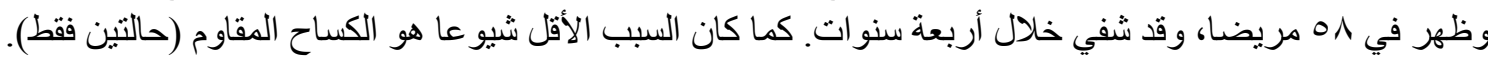

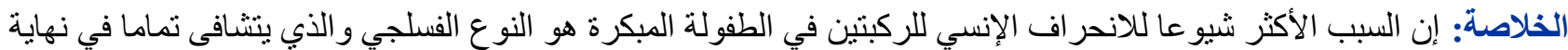

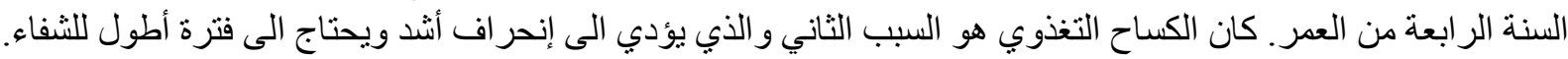

G enu varus means that the leg distal to knee is displaced toward the median plane (1). Bilateral Genu varus (bowlegs) is an extremely common pediatric deformity, that they are considered to be normal stages of development; the parents should be reassured and the child should be seen at intervals of 6 months to record progress $^{(2,3)}$. 
Most pediatric genu varuses are physiologic in nature and resolve spontaneously without any intervention. Accordingly, an accurate knowledge of the natural history of this angular deformity allows us to avoid unnecessary treatments (2). Physiological genu varus is bilateral and symmetrical and corrected with farther growth after the age of three years, no treatment is necessary ${ }^{(4)}$. Bilateral genu varus can be recorded clinically by measuring the distance between the knees (intercondylar distance), the maximum normal value is less than $6 \mathrm{~cm}$, with absence of any pathological causes it is named as physiological genu varus ${ }^{(1,3,5)}$. Although benign and self-limiting in most cases, these deformities sometimes cause a great concern to the parents and the relatives, such anxieties frequently lead physicians to conduct physical or radiological examinations ${ }^{(5)}$.

In ricketic patients, the most frequent deformity is genu varus ${ }^{(6)}$. Nutritional rickets is still the most common form of growing bone disease despite the efforts of health care providers to reduce the incidence of the disease. . $^{(7,8,9)}$

The aim of this study is to find the common causes of genu varus, and to evaluate the style of its correction.

\section{PATIENTS AND METHODS}

During the period between February 2005 and February 2010, 213 patients with bilateral genu varus whose parents gave their consent were included in the study. All patients were in their second year of age at presentation (mean age 1.4 year). The patients recruited from Orthopedic Outpatient's Clinic in Aljumhoori Teaching Hospital in Mosul, 110 were females and 103 were males. They were followed up for a period of two to six years (mean 3.6 years). All_cases that had, unilateral genu varus, history of trauma to knee or infections around knee, skeletal dysplasias, and other abnormalities related to the lower limb were excluded. Fourteen patients who didn't complete follow up were also excluded.

All patients were examined clinically, physical examination included assessment of height, weight. Skull, spine, chest examination, neurologic examination, lower and upper extremities examination were performed. Wrist and knee $x$ ray performed only if there was evidence of rickets or the distance between two knees were more than $6 \mathrm{~cm}$.

The diagnosis of nutritional rickets was based on a combination of clinical, radiological, and biochemical criteria, and confirmed by the responses to treatment. Serum calcium, phosphate, alkaline phosphatase were performed if there was clinical evidence of rickets to confirm the diagnosis. Children with nutritional rickets were treated by a single large oral or intramuscular dose of vitamin D (600,000 IU) along with oral calcium and supplementary vitamin $\mathrm{D}$ as well as advice on diet and sunlight exposure.

Measurement techniques: Child was allowed to lie in supine position with the hip, knee in maximum extension and lower limbs together so that the two medial malleoli touch. The intercondylar distances were measured using a tape measure. Intercondylar distance is the distance between the right and left medial femoral condyles. The Intercondylar distance was considered to be zero when there is no demonstrable intercondylar distance (knee in contact). The knee alignment was considered to be varus when there is a demonstrable intercondylar distance while the two medial malleoli are touching. The measurement repeated every 6 months, the mean of intercondylar distances were calculated for physiological genu varus group and for ricketic patients.

Statistical analysis: The data were analyzed with Microsoft excel version 2007. The prevalence was presented as percentage (\%). The statistical analysis included the mean and standard deviation. Student's $t$-test was used to ascertain the significance of differences between mean values of two continuous variables.

\section{RESULTS}

Physiological genu varus was the commonest cause $73.8 \%$ (153 patients, 78 were males and 75 were females). Nutritional rickets was the second cause, 58 patients ( 31 female and 27 males). This group treated by vitamin $\mathrm{D}$ derivatives. Two patients had vitamin D resistant rickets (familial hypophosphataemia) from same family (Table 1). 
Table 1. The changes in means of intercondylar distance during patients followup.

\begin{tabular}{|c|c|c|c|}
\hline \multirow{2}{*}{$\begin{array}{c}\text { Time of assessment } \\
\text { during follow up }\end{array}$} & \multicolumn{2}{|c|}{$\begin{array}{c}\text { Intercondylar distance in centimeters in patients had genu varus } \\
\text { (means and standard deviation) }\end{array}$} \\
\cline { 2 - 4 } & $\begin{array}{c}\text { Physiological genu varus } \\
(\mathbf{1 5 3 )}\end{array}$ & $\begin{array}{c}\text { Nutritional rickets genu } \\
\text { varus (58) }\end{array}$ & $\begin{array}{c}\text { Hypophosphataemic } \\
\text { rickets (2) }\end{array}$ \\
\hline At presentation & $3.42 \pm 0.93$ & $4.22 \pm 0.92$ & 5.5 \\
\hline 6 months & $2.23 \pm 0.67$ & $3.8 \pm 1.10$ & 5 \\
\hline 1 year & $1.84 \pm 0.86$ & $2.66 \pm 0.93$ & 6 \\
\hline 1.5 year & $0.35 \pm 0.48$ & $1.63 \pm 0.85$ & 6 \\
\hline 2 years & 0 & $0.82 \pm 0.78$ & 6 \\
\hline 2.5 years & 0 & $0.58 \pm 0.70$ & 6.5 \\
\hline 3 years & 0 & $0.30 \pm 0.50$ & 6.5 \\
\hline 3.5 years & 0 & $0.08 \pm 0.28$ & 6 \\
\hline 4 years & 0 & 0 & \\
\hline
\end{tabular}

The mean of intercondylar distances in physiological genu varus at presentation was 3.42 $\pm 0.93 \mathrm{~cm}$ corrected in all patients within two years (Table 1) (Fig. 1). The mean of intercondylar distances in nutritional rickets at presentation was $4.22 \pm 0.92 \mathrm{~cm}$ corrected in all patients within four years (Table 1) (Fig. 1); while the mean of intercondylar distances in familial hypophosphateaemic rickets persisted in spite of treatment (Table 1). There was highly significant difference between the means of intercondylar distances in physiological genu varus, and the genu varus associated with nutritional rickets at presentation ( $P$ value $<0.0001)$. The mean of intercondylar distances in patients had vitamin $D$ resistant rickets (familial hypophosphataemia) at presentation was $4.5 \mathrm{~cm}$, increased in last followup to $6 \mathrm{~cm}$ (increased with growth of child).

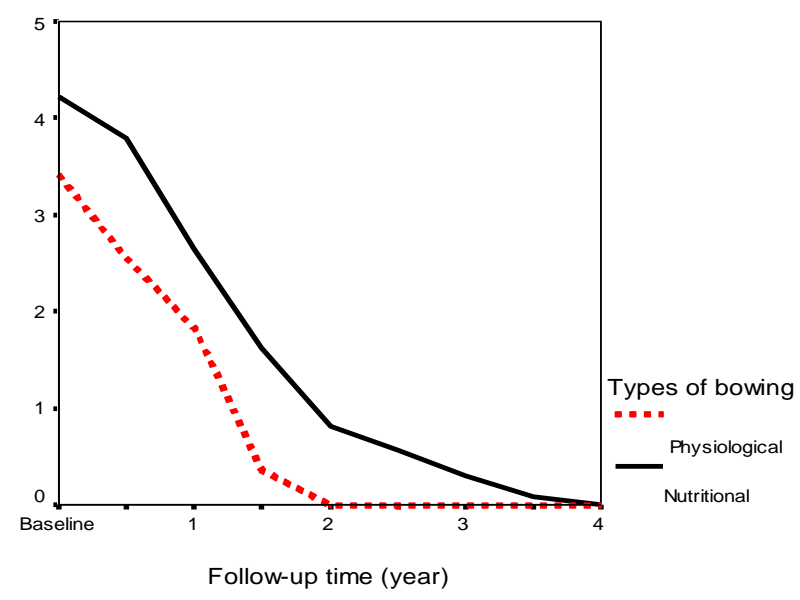

Figure 1. Improvement in inter condylar distance of physiological and nutritional ricket genu varus during period of follow-up.

\section{DISCUSSION}

In our patients the commonest cause of bilateral genu varus was the physiological type; its correction was spontaneously without any treatment in two years. The correction occurs earlier than that reported by Joo et al in Korea ${ }^{(2)}$. All reports agree that the physiological genu varus is a normal condition in early childhood which does not require any treatment ${ }^{(3,10,11)}$. In agreement with our results, Do TT reported that lower extremity bowing is a normal physiologic process that commonly occurs in walking children under the age of 2 years, after this age, any significant amount of residual bowing is abnormal ${ }^{(12)}$. The report of Yoo et al, demonstrates that, knee angle was in genu varus before 1 year, neutral at 1.5 year $^{(5)}$. A relevant and correct understanding of the development of the knee angle and limb alignment would prevent unreasonable apprehension by parents and relatives, and unnecessary diagnostic measurements, such as repeated exposure to radiation, and the inappropriate application of orthotics or bracing, which are not often costeffective and might even hinder natural development ${ }^{(5)}$.

In this study the second cause of genu varus was nutritional rickets, with significantly greater intercondylar distance in comparison with that of physiological genu varus (Table 1). It was corrected with treatment in longer period; their correction completed within 4 years (Fig. 1). This might be explained by the severity of genu varum and delay of treatment. The common presence of rickets as a cause of genu varus is expected in our 
community with many nutritional problems and lack of sun exposure due to indoor living, and clothing pattern, inspite of sunny climate. Nutritional rickets remains prevalent in developing regions of the world $^{(4,8)}$. In estern Europe the nutritionl rickets as a cause of genu varum still common. ${ }^{(13)}$ In agreement with our study, Ozkan B in Turkey reported that genu varus is common in nutritional ricket; the same reported in Nigeria by Onyiriuka $\mathrm{AN}$ et al who showed also that genu varus was common in nutritional rickets, and its clinical features healed in 3-5 months after treatment ${ }^{(7,14)}$. The report of Benere et al revealed that nutritional rickets is highly prevelant in Middle East, and considered as multi factorial condition, results from lack of exposure to sun and dietary deficiency ${ }^{(6)}$. Two cases of our patients had severe genu varus that was associated with vitamin $D$ resistant rickets (hypophosphataemia) and increased with growth due to difficulty in monitoring their state and lack of phosphate therapy.

The limitation in this study is that it depends on intercondylar distance which has the disadvantage of being relative measurements that are affected by the child's size. More studies are indicated on normal population to assess the variability in knee angles according to the ages in children in our community.

We concluded that the most common cause of bilateral genu varus was physiological, that corrected spontaneously without any treatment within two years. Nutritional rickets was the second cause which lead to more severe genu varus, and delayed its correction after treatment, while the genu varus associated with vitamin D resistant rickets (hypophosphataemia) increased with growth.

\section{REFERENCES}

1. Solomon L, Karachalios T. The Knee. In: Solomon L, Warwick D, Nayagam S, editors. Apley's System of Orthopaedic and Fractures. $9^{\text {th }}$ ed. London: Arnold, 2010.p. 547585.

2. Joo YS, Park HW, Park KB, Kim BS, Park JS, Kim H W. A New Classification for Idiopathic Genu Vara. Yonsei Med J. 2007; 48(5): 833-838.

3. Herring JA. Disorders of the leg. In: Tachdjian's pediatric orthopaedics. $4^{\text {th }}$ edition. Dallas: Saunders Elsevier; 2008.p.973-1033.
4. Bentley G. Affections of knee joint. In: Duthie RB, Bentley G. Mercer's orthopaedic surgery. $9^{\text {th }}$ edition. London: Arnold; 1996.p.1125- 1190.

5. Yoo J H, Choi I H, Cho T J, Chung C Y, Yoo W J. Development of Tibiofemoral Angle in Korean Children. J Korean Med Sci. 2008; 23(4): 714-717.

6. Bener A, Hoffmann GF. Nutritional Rickets Among Children in a Sun Rich Country. Int $\mathrm{J}$ Pediatr Endocrinol 2010; 27: 1- 7.

7. Özkan B. Nutritional Rickets. J Clin Res Pediatr Endocrinol. 2010 December; 2(4): 137-143.

8. Solomon L. Metabolic and endocrine disorders. In: Solomon L, Warwick D, Nayagam S. Apley's System of Orthopaedic and Fractures. $9^{\text {th }}$ ed. London: Arnold,2010. p.117-150.

9. Carva Iho NF, Kenney RD, Carrington PH, Hall DE. Severe nutritional deficiencies in toddlers resulting from health food milk alternatives. Pediatrics. 2001;107(4): 46.

10. Sass $P$, Hassan G. Lower Extremity Abnormalities in Children. Am Fam Physician. 2003;68(3):461468.

11. Ezeuko V C, Owah S, Ukoima H S, Ejimofor O C, Aligwekwe A U, Bankole L. Clinical study of the chronological changes in knee alignment pattern in normal south- east Nigerian children aged between 0 and 5 years. Rev Electron Biomed / Electron $\mathrm{J}$ Biomed 2010;1:16-21.

12. Do TT. Clinical and radiographic evaluation of bowlegs. Curr Opin Pediatr. 2001;13(1):42-6.

13. Voloc A, Esterle L, Nguyen TM et al High prevalence of genu varum/valgum in European children with low vitamin $D$ status and insufficient dairy products/calcium intakes. Eur $\mathrm{J}$ Endocrinol 2010; 163(5):811-7.

14. Onyiriuka AN, Abiodun PO, Onyiriuka FU. Nutritional rickets in childhood. Curr Pediatr Res. 2012;16:129-135. 